\title{
Evaluation of the application of enemas containing sucralfate in tissue content of neutral and acid mucins in experimental model of diversion colitis ${ }^{1}$
}

\author{
Felipe Mendonça Chaim ${ }^{\mathrm{I}}$, Daniela Tiemi Sato ${ }^{\mathrm{II}}$, Murilo Rocha Rodrigues ${ }^{\mathrm{II}}$, Alice Moreira Dias ${ }^{\mathrm{III}}$, Paulo Pedroso Silveira Júnior ${ }^{\mathrm{III}}$, \\ José Aires Pereira' ${ }^{\mathrm{IV}}$, Carlos Augusto Real Martinez ${ }^{\mathrm{V}}$
}

DOI: http://dx.doi.org/10.1590/S0102-8650201400150001

${ }^{\mathrm{I}}$ Fellow Master degree, Postgraduate Program in Health Sciences, Sao Francisco University (USF), Bragança Paulista-SP, Brazil. Acquisition and interpretation of data, manuscript writing.

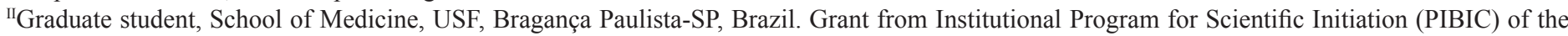
National Council of Scientific and Technological Development (CNPq), Ministry of Science, Technology and Inovation, Brazil. Acquisition of data, histological examinations, surgical procedures.

III Graduate student, School of Medicine, USF, Bragança Paulista-SP, Brazil. Acquisition of data, histological examinations, surgical procedures.


and histochemical analysis.

vPhD, Associate Professor, Postgraduate Program in Health Sciences, USF, Bragança Paulista-SP, Brazil. Associate Professor, Department of Surgery, Campinas State University (UNICAMP), Campinas-SP, Brazil. Intellectual and scientific content of the study, manuscript writing, critical revision.

\section{ABSTRACT}

PURPOSE: To evaluate the effects of sucralfate on tissue content of neutral and acids mucins in rats with diversion colitis.

METHODS: Thirty-six rats were submitted to a proximal right colostomy and a distal mucous fistula. They were divided into two groups according to sacrifice to be performed two or four weeks after intervention. Each group was divided into three subgroups according daily application of enemas containing saline, sucralfate at $1.0 \mathrm{~g} / \mathrm{kg} /$ day or $2.0 \mathrm{~g} / \mathrm{kg} / \mathrm{day}$. Colitis was diagnosed by histological analysis and neutral and acid mucins by Periodic Acid Schiff and Alcian Blue techniques, respectively. The contents of mucins were quantified by computer-assisted image analysis. Student's t paired and ANOVA test were used to compare the contents of both types of mucins among groups, and to verify the variance with time, establishing level of signification of $5 \%$ for both ( $\mathrm{p}<0.05$ ).

RESULTS: Enemas containing sucralfate improves the inflammation and increases the tissue contents of neutral and acid mucins. The content of neutral mucins does not change with the time or concentration of sucralfate used, while acid mucins increases with concentration and time of intervention.

CONCLUSIONS: Sucralfate enemas improve the inflammatory process and increase the tissue content of neutral and acid mucins in colon without fecal stream.

Key words: Colitis. Colostomy. Fatty Acids, Volatile. Mucins. Sucralfate. Image Processing, Computer-Assisted. Rats. 


\section{Introduction}

Glotzer et al. ${ }^{1}$ were the first to describe the development of an inflammatory process in the mucosa of colon segments without fecal stream. They called this new form of inflammatory bowel disease (IBD) diversion colitis (DC). Subsequently, it has been demonstrated that the etiopathogenesis of DC is related to intraluminal deficiency of short-chain fatty acids (SCFAs), the main energy substrate for the cells of the colon epithelium ${ }^{2}$. The most common histological finds in patients with DC include epithelial erosions or ulcerations, decreased length or modified architecture of the colonic glands, inflammatory infiltrate and, depletion of the number of goblet cells, with consequent modifications on tissue content of mucins ${ }^{2-4 T h e s e}$ histological alterations are similar to those found in other forms of IBD, particularly in the distal proctitis founded after pelvic radiotherapy and in rectal compromising of ulcerative colitis (UC)

The mucous layer covering the colon epithelium is the first line of defense against invasion of the intestinal wall by bacteria and antigen that are present in the intestinal lumen ${ }^{4,5}$. Most of the protective effect provided by the mucous layer relates to the presence of mucins, which are the predominant glycoproteins in the chemical composition of colonic mucous ${ }^{6-8}$. Mucins in addition to forming a mechanical barrier exhibit antimicrobial activity that protects the intestinal wall against existing pathogens in the intestinal lumen'. The histochemical expression of mucins in the colonic mucosa is well known and, selectively, the presence of neutral and acid mucins can be demonstrated ${ }^{10}$. The proportions between neutral and acid mucins may be modified in IBD and changes to the tissue expression of this glycoprotein in the colon mucosa of patients with UC and Crohn's disease have already been demonstrated ${ }^{11,12}$. The capacity of the colonic epithelium to produce mucins depends on adequate supply of SCFAs ${ }^{7}$. Recent studies have shown the importance of maintaining the supply of SCFAs, particularly butyrate, in order to have adequate gene expression relating to mucin formation and content of the glycoprotein ${ }^{4,5,8,13}$.

Despite the histopathological similarities between UC and DC, few studies has evaluated the modifications in the tissue contents and pattern of expression of neutral and acid mucins on glands of the colonic mucosa without fecal stream ${ }^{4,5,13}$. The results of these studies showed that the deviation of the fecal stream reduce the content and modify the pattern of tissue expression of neutral and acid mucins. In other words, the deficiency in the supply of SCFAs can modify the mucus that overlying the colonic mucosa, reducing the effectiveness of this first line of defense against luminal aggression ${ }^{5,13}$.
Sucralfate (SCF) is a basic aluminum salt of sucrose octasulphate which was employed for prevention and treatment of several gastrointestinal diseases ${ }^{14}$. SCF has used as a topical treatment to healing several types of epithelial wounds such as venous ulcers, mucositis and perianal wounds ${ }^{15,16}$. The molecule of SCCF has other properties such as antioxidant, stimulating the formation of gastrointestinal mucus, increase the production of prostaglandins and epidermal growth factor (EGF) $)^{14}$. Kochhar et $a l .{ }^{16}$ were the first author to demonstrate the efficacy of enemas containing SCF in control of rectal bleeding due to radiation proctitis (RP). Since then, a string of well-conducted studies have confirmed the beneficial therapeutic effects of the substance in clinical, endoscopic and histological improvement in patients with $\mathrm{RP}$, as well as in other forms of IBD where occur the formation of ulcers in the colonic mucosa, such as UC and solitary rectal ulcer $^{17,18}$. Despite the DC course with the formation of superficial epithelial ulcerations and aphthous ulcers in the colonic mucosa, to the best of our knowledge, the effects of SCF on tissue expression of mucins has not yet been evaluated in patients or experimental models of DC. Therefore, the objective of this study is to determine the effects of application of daily enemas with SCF on tissue content of mucins in colonic mucosa devoid of the fecal stream.

\section{Methods}

The experiments were performed in accordance with the principles outlined by Federal Law n 11.794 (10/08/2008) and were approved by the Ethics Committee in Animal Research of Sao Francisco University (No 2211/2007).

Thirty-six male, SPF, Wistar rats (300-350g) were obtained from the Sao Francisco University, School of Medicine, barrier facility and maintained on light/dark cycles of 12 hours, and fed a standard rodent chow diet. They were deprived of food, but not water, for $24 \mathrm{~h}$ prior to the surgical procedure.

\section{Surgical technique}

The diversion of the fecal stream was performed in all animals under general anesthesia by intramuscular administration of $0.1 \mathrm{ml} / 100 \mathrm{~g}$ of a $1: 1(\mathrm{v} / \mathrm{v})$ solution of ketamine $(50 \mathrm{mg} / \mathrm{ml})$ and xylazine $(20 \mathrm{mg} / \mathrm{ml})$. The abdomen was shaved, and a $3 \mathrm{~cm}$ long midline incision was made. The left colon was exteriorized and sectioned in its mid-portion, corresponding to the descending colon, approximately $3 \mathrm{~cm}$ above the Peyer's lymphoid patch located in the rectal-sigmoid transition. Two circular skin pellets, $3 \mathrm{~mm}$ in diameter and $3 \mathrm{~cm}$ apart, were made in the left side 
of the abdominal wall at the same vertical level. The proximal end of the colon was exteriorized through the cranial cutaneous orifice, and the distal stoma was exteriorized through the caudal skin opening after splitting the abdominal wall muscles. The proximal end and the distal stoma were fixed to the skin with full-thickness sutures. Before the fixation of distal stoma to the skin, the distal colon was cleaned by means of an infusion of a physiologic solution until the fecal contents were completely removed. The abdominal incision was closed in two stages (aponeurosis and the skin). In this way, two colostomies were performed: the proximal colostomy as a terminal colostomy with intestinal transit and the second colostomy, as a distal stoma devoid of the fecal stream. Rats were maintained in individual cages, without particular care being taken with regard to the stomas and abdominal incisions.

\section{Experimental groups}

The animals were divided into two experimental groups with 18 animals each according the euthanasia had done after two or four weeks. Each experimental group was divided into six subgroups ( $n=6)$ according to the intervention solution employed and time of intervention. In the first and second subgroups, 12 animals received daily rectal enemas containing $40 \mathrm{ml}$ of $0.9 \%$ saline solution (control subgroup) at $37^{\circ} \mathrm{C}$ for two weeks $(n=6)$ and four weeks $(n=6)$. In the second subgroup, 12 animals received daily rectal enemas containing $40 \mathrm{ml}$ of SCF (Sigma-Aldrich, St Louis, MO, USA) at a concentration of $1.0 \mathrm{~g} / \mathrm{kg}$ for two weeks $(n=6)$ and four weeks $(n=6)$. Finally, 12 animals of the third subgroup received daily enemas containing $40 \mathrm{ml}$ of SCF at a concentration of $2.0 \mathrm{~g} / \mathrm{kg}$ for two weeks $(\mathrm{n}=6)$ and four weeks $(n=6)$. In order to standardize the speed and time of application, the enemas were administered in all animals with an infusion pump whose speed was standardized at $2 / \mathrm{ml} / \mathrm{min}$.

\section{Sample collection}

Upon completion of the pre-determined irrigation period, the animals were anesthetized as described above, and the midline incision was opened again. In both groups, specimens were taken from the intra-abdominal part of the excluded (colon without fecal stream) subjected to irrigation with the proposed substances. The removed specimen, measuring approximately $4.0 \mathrm{~cm}$, was longitudinally opened through the anti-mesenteric border fixed in a piece of cork and referred to histological and histochemical analysis.

\section{Histological and histochemical analysis}

Fragments prepared for histological analysis were immersed in $10 \%$ neutral formalin buffer (Sigma-Aldrich, St. Louis, MO, USA) for $24 \mathrm{~h}$, dehydrated by exposure to increasing ethanol concentrations, and embedded in paraffin. Thereafter, sections of tissue were cut at $5 \mu \mathrm{m}$ on a rotary microtome (Leica Biosystems, Nussloch, Germany), mounted on a glass slide, cleared, hydrated and stained with hematoxylin-eosin (HE) for evaluation of the presence of colitis. Slide analysis was performed with optical microscope (Eclipse DS-50, Nikon Inc., Osaka, Japan) with final magnification of x200. Photomicrographs were taken with a digital video-capture camera (DS-Fi-50; Nikon Inc., Osaka, Japan) coupled to the microscope body and digitized by a computer system of image analysis (NISElements; Nikon Inc., Osaka, Japan). The diagnosis of colitis was made based on presence of three independent histological parameters: reduction of the crypt length, neutrophil infiltration of the mucosa and epithelial loss. These variables were stratified as crosses, according to the degree of each, as follows: a) + absent or no alterations; b) ++ when intensity was mild d) +++ moderate and e) ++++ intense. For all variables analyzed, the final value considered for each animal was the mean value after quantification of three distinct histological fields.

The tissue expression of the neutral mucins was determined individually by means of the histochemical technique of Periodic Acid Schiff (PAS), while the expression of acid mucins was determined using the Alcian Blue (AB) technique. The neutral mucins stained magenta, while the acid mucins stained blue ${ }^{19}$. The pattern of tissue expression was by a pathologist with experience of diseases of the digestive tract who was unaware of the origin of the material and the objectives of the study.

\section{Image processing, computer-assisted}

The tissue content of neutral and acid mucins was quantified by means of image processing computer-assisted and was always performed in a focal field in which there were at least three complete and contiguous colonic crypts, with a magnification of $\mathrm{x} 200$. The images selected were captured on a video camera that had been coupled to an optical microscope. These images were processes and analyzed using the NIS-Elements 3.1 software (Nikon Inc., Osaka, Japan), installed in a microcomputer. By means of colored histograms in RGB system the software determined the color intensity in number of pixels in each field selected, and transformed the final data into percentage expressions by analyzed fields (\%/fields). The final value taken for each field measured in the segments with and without intestinal transit was the mean of the values found from evaluating three different fields. 


\section{Statistical analysis}

The statistical analysis on the results obtained was performed by taking the significance level of $5 \%(\mathrm{p}<0.05)$. The data from each colon segment analyzed, in each experimental group, were expressed as the mean value with the respective standard error, and were analyzed using the Biostat for Windows statistical software (version 5.0). To compare the mucin content in the segments with and without transit, Student's t paired test was used. To analyze the variance in the mucin expression between the different experimental groups, ANOVA was used with the Newman-Keuls post-test.

\section{Results}

Figure 1A shows the colonic epithelium without fecal stream submitted to intervention with S.F. $0.9 \%$ for 4 weeks, while Figure $1 \mathrm{~B}$ shows the colon segment without fecal stream irrigated with SCF at concentration of $2.0 \mathrm{~g} / \mathrm{kg} /$ day.

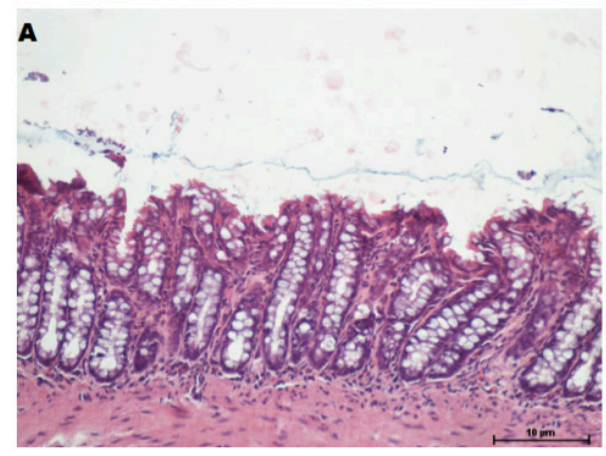

FIGURE 1 - A. Colonic mucosa devoid of the fecal stream submitted to intervention with saline for four weeks. Note the epithelial loss with formation of superficial ulcers and irregularity of the colonic glands (HE-x100). B. Colonic mucosa devoid of the fecal stream submitted to intervention with SCF $(2.0 \mathrm{~g} / \mathrm{kg} /$ day $)$ for four weeks. It's possible verify the formation of a protective layer of SCF on the colonic mucosa, preservation of the epithelial colonic surface without the formation of ulcers.

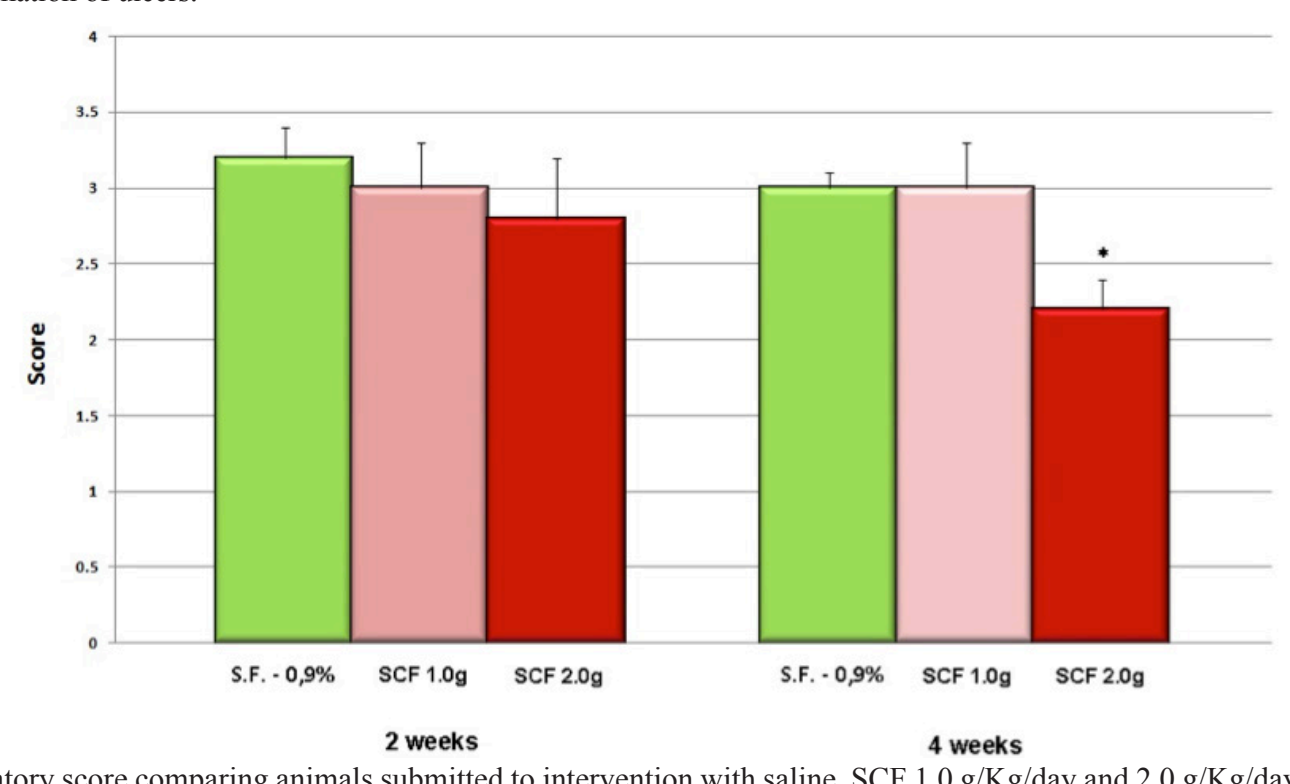

FIGURE 2 - Inflammatory score comparing animals submitted to intervention with saline, SCF $1.0 \mathrm{~g} / \mathrm{Kg} / \mathrm{day}$ and $2.0 \mathrm{~g} / \mathrm{Kg} / \mathrm{day}$ for two and for weeks. $*=$ significant $(\mathrm{p}<0.05)$. Student $\mathrm{t}$ test. submitted to intervention with saline, SCF $1.0 \mathrm{~g} / \mathrm{kg} / \mathrm{day}$ and SCF 2.0 $\mathrm{g} / \mathrm{kg} /$ day for two and four weeks.

Figure 3A show the tissue expression of neutral mucins, evaluated in segments without fecal stream submitted to intervention with S.F. $0.9 \%$ for four weeks, while Figure $3 \mathrm{~B}$ shows the colon segment without fecal stream irrigated with SCF at concentration of $2.0 \mathrm{~g} / \mathrm{kg} / \mathrm{day}$.

Figure 4 shows the mean, with respective standard error, from quantification of neutral mucins comparing colon segments without intestinal transit, submit to daily intervention with saline and $\mathrm{SCF}$ at concentration of $1.0 \mathrm{~g} / \mathrm{kg}$ and $2.0 \mathrm{~g} / \mathrm{kg}$. We found a significant increase in tissue content of neutral mucins in animals subjected to irrigation with SCF compared to animals irrigated with S.F. $0.9 \%$, regardless of the concentration and duration of intervention. The tissue contents of neutral mucins did not vary with the time of intervention established, independent of concentration.

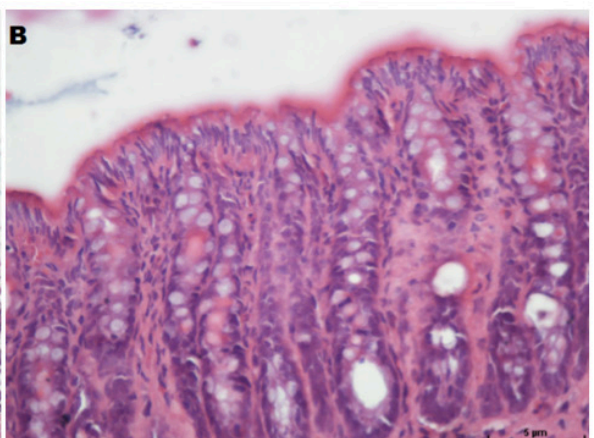




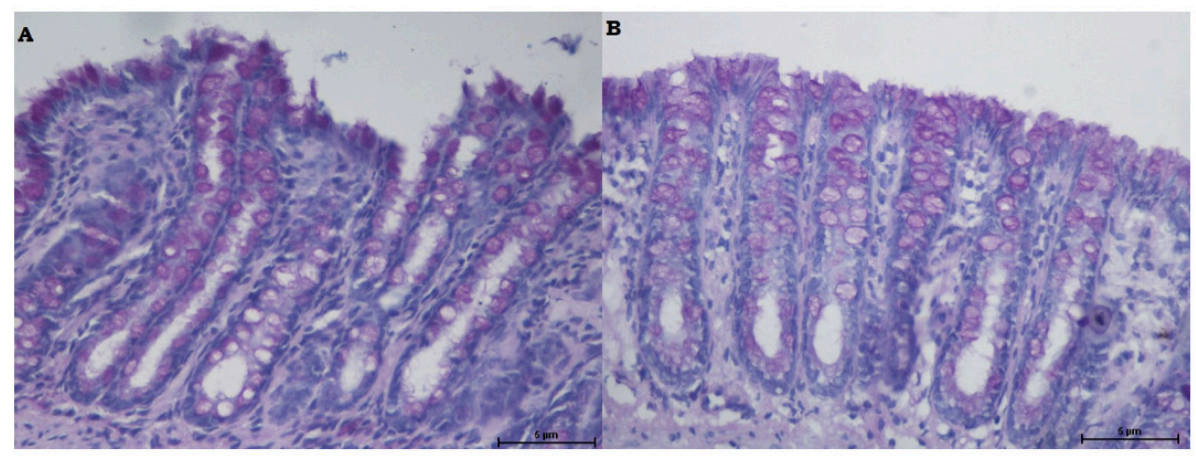

FIGURE 3 - A. Tissue content of neutral mucins in animals submitted to intervention with saline for four weeks. It's possible verify loss of epithelium surface, distortion of the colon crypts and reduction of tissue content of neutral mucins in colon glands (PAS-x200). B. Neutral mucins on glands of colonic mucosa devoid of the fecal stream submitted to intervention with SCF $2.0 \mathrm{~g} / \mathrm{Kg} /$ day for four weeks. The epithelial surface is preserved, and the neutral mucin expression occurs uniformly along the colonic glands (PAS-x200).

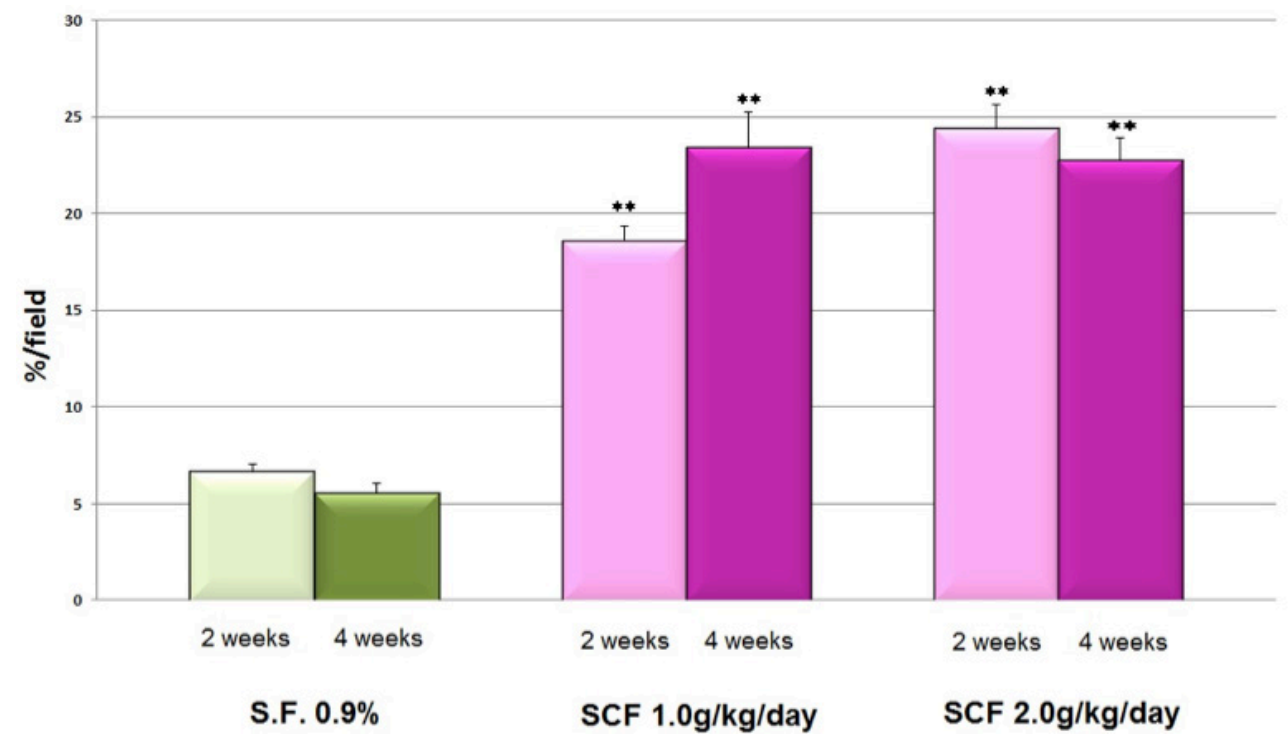

FIGURE 4 - Tissue content of neutral mucins comparing animals submitted to intervention with saline, SCF $1.0 \mathrm{~g} / \mathrm{Kg} / \mathrm{day}$ and $2.0 \mathrm{~g} / \mathrm{Kg} / \mathrm{day}$ for two and for weeks. $* *=$ significant $(\mathrm{p}<0.01)$. Student $\mathrm{t}$ test.

Figure 5A shows the tissue expression of acid mucins, evaluated using the Alcian-Blue technique in colonic segments without fecal stream submitted to intervention with S.F. $0.9 \%$ for four weeks, while Figure 5B shows the colon segment without fecal stream irrigated with SCF at concentration of $2.0 \mathrm{~g} / \mathrm{kg} /$ day.

Figure 6 shows the mean, with respective standard error, from quantification of acid mucins comparing colon segments without intestinal transit, submmit to daily intervention with S.F.0.9\% and $\mathrm{SCF}$ at concentration of $1.0 \mathrm{~g} / \mathrm{kg}$ and $2.0 \mathrm{~g} / \mathrm{kg}$. We found a significant increase in tissue content of acid mucins in animals subjected to irrigation with SCF compared to animals irrigated with S.F. 0.9\%, regardless of the concentration and duration of intervention. The tissue contents of acid mucins increase with the concentration established, independent of the time.

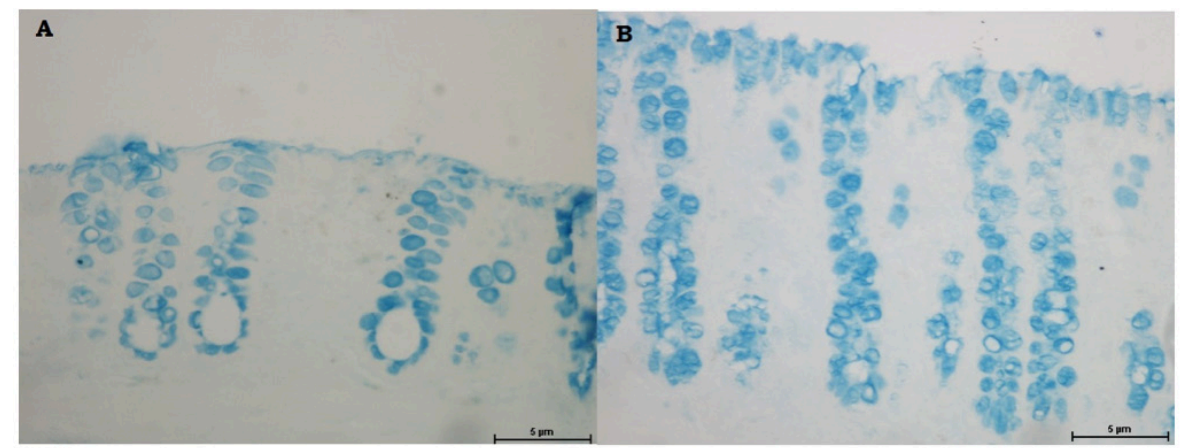

FIGURE 5 - A. Tissue content of acid mucins in animals submitted to intervention with saline for four weeks. Reduction of tissue content of acid mucins in colon glands (AB-x100). B. Acid mucins on glands of colonic mucosa devoid of the fecal stream submitted to intervention with SCF $2.0 \mathrm{~g} /$ $\mathrm{Kg} /$ day for four weeks. The expression of acids mucin occurs uniformly along the colonic glands (AB-x200). 


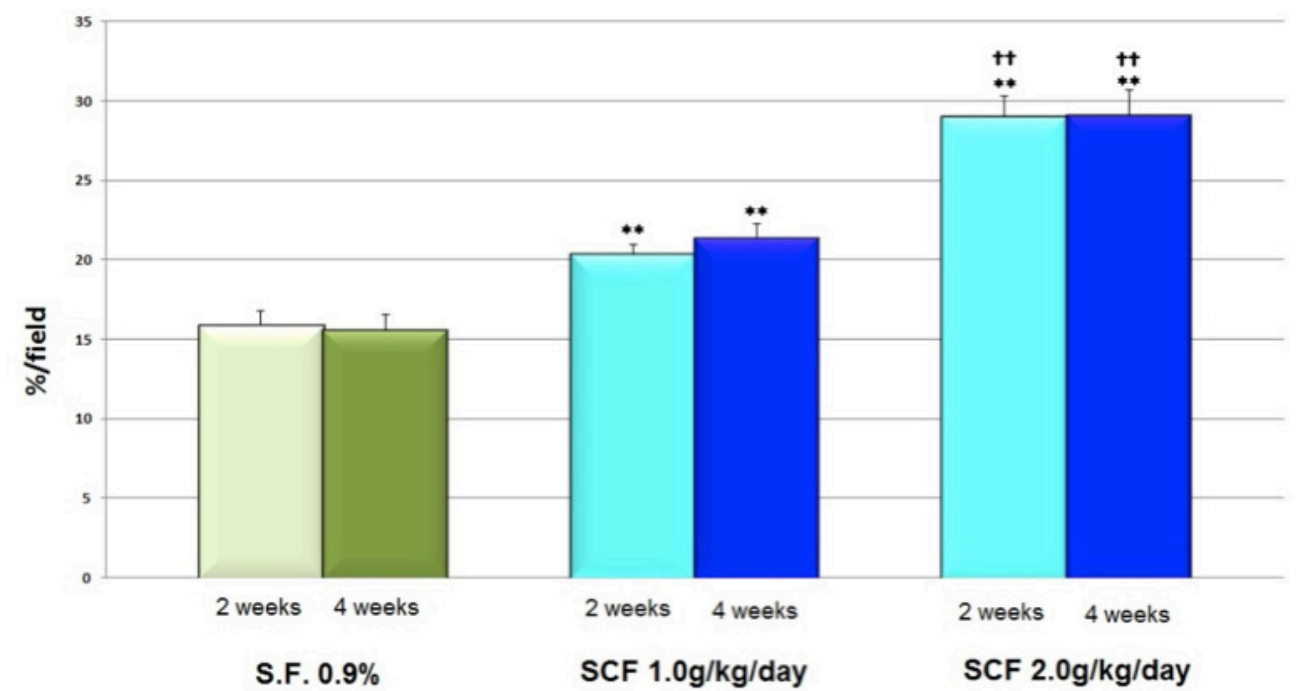

FIGURE 6 - Tissue content of acid mucins comparing animals submitted to intervention with saline, SCF $1.0 \mathrm{~g} / \mathrm{Kg} / \mathrm{day}$ and $2.0 \mathrm{~g} / \mathrm{Kg} / \mathrm{day}$ for two and for weeks. ${ }^{* *}=$ significant $(\mathrm{p}<0.01) * * \mathrm{SCF} 1.0 \mathrm{~g} / \mathrm{kg} / \mathrm{day}$ and SCF $2.0 \mathrm{~g} / \mathrm{kg} / \mathrm{day} \times$ Saline. ${ }^{\dagger} \mathrm{SCF} 1.0 \mathrm{~g} / \mathrm{kg} / \mathrm{day} \times \mathrm{SCF} 2.0 \mathrm{~g} / \mathrm{kg} / \mathrm{day} \mathrm{Student} \mathrm{t}$ test.

\section{Discussion}

DC is defined as an IBD that affects colorectal segments without fecal stream ${ }^{2}$. A variety of theories have been put forward to explain the etiopathogenesis of DC. Prominent among these is a theory that relates the appearance of this disease to decreased

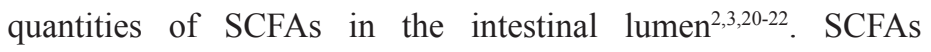
are the main energy source for colonocytes and account for approximately $80 \%$ of the energy needs of the colon epithelium ${ }^{20}$. In colon segments without fecal stream, absence of the diet fibers impedes the formation of SCFAs and also their absorption and use by the epithelial cells. Recent studies have shown that an absence of SCFAs modifies energetic metabolism of the mitochondrial respiratory chain of the colonocytes leading an increase on production of reactive oxygen species (ROS) ${ }^{23}$. The increased production of ROS in a tissue recognized to be deficient in antioxidant systems can cause oxidative damage to the cells of the colonic epithelium ${ }^{23}$. It has been shown the deleterious effects of ROS against the mechanisms of defense of colonic epithelial barrier, in particular the mucus layer overlying the intestinal mucosa and the cellular adhesion moleculles ${ }^{5,13,24-25}$. These studies showed a relationship between increased of ROS production and reduction in tissue content of neutral and acid mucins in colon segments without fecal steam ${ }^{5-13}$. Reinforcing the importance of oxidative stress in the intestinal epithelium aggression in colonic segments devoid of fecal stream had been demonstrated that the application of enemas containing substances with antioxidant activity, such as 5-aminosalicylic acid and n-acetylcysteine, improves tissue damage by reducing levels of ROS by cells of the colonic mucosa $\mathrm{a}^{26-27}$.
The main function of mucus is to serve as protection for the epithelial cells of the intestinal mucosa, against aggression caused by enzymes, antigens and bacteria that are present in the intestinal lumen ${ }^{6,9}$. The expression of mucins in the colon epithelium is well known and can be categorized by histochemical techniques as neutral or acid ${ }^{4,13}$. The proportion among all types of mucins is usually constant in the mucosa of normal colon tissue, but may undergo changes in various diseases ${ }^{5}$. The capacity for mucin synthesis shown by the goblet cells of the colon mucosa depends on an adequate supply of energy substrate ${ }^{7,8}$. Reductions in the supply of SCFAs, as occurs during intestinal diversion operations, are accompanied by morphological and functional changes, thereby causing reductions in protein synthesis capacity ${ }^{5,8}$. The mechanisms through which shortages of SCFAs lead to lower capacity for mucins production are still not completely clear. Studies have shown that intestinal diversion reduces the quantities of dietary fiber and modifies the bacterial populations in the segment excluded and it decreases the production of SCFAs, thereby causing a state of nutritional deficiency for the cells of the colon mucosa $a^{5,20,21,28}$. This nutritional deficiency reduces the mucin synthesis capacity of these cells ${ }^{7}$. Reinforcing this evidence, studies have shown that administration of SCFA enemas increases the mucin synthesis capacity of the colon mucosa cells, while administration of enemas containing sodium bromo-octanoate (a powerful inhibitor of SCFA metabolization) completely blocks mucin synthesis and causes the appearance of colitis ${ }^{8,28}$. SCFAs also induce the expression of various genes that transcribe mucins, thereby increasing the expression of $M U C-2$ around twentyfold ${ }^{7,8}$. SCFAs increase cell metabolism by more than $80 \%$ and the production and secretion of mucins by the colon epithelium more 
than twentyfold ${ }^{8,29}$. Recent research has also demonstrated that shortages of SCFAs greatly reduces the expression of the $M U C$ 2 gene, which is the main agent responsible for transcription of the protein fraction of colon mucins ${ }^{8,30}$. Two studies adopting an experimental model of DC showed that the deviation of the fecal stream reduce the tissue content of neutral and acid mucins, particularly scialomucins quantified by computer assisted image analysis, confirming the importance of correct supply of SCFAs in maintaining the synthesis of the glycoprotein ${ }^{5,13}$. All these points reinforce the important role played by SCFAs in relation to the capacity of the colon epithelium to produce mucins and consequently to protect the mucosa against aggression coming from the intestinal lumen ${ }^{5,7,13,31}$.

These features suggest that the ideal substance for the treatment of DC should have as principal precepts: enhance protection of the intestinal epithelium that lost the protection afforded by the mucus layer, stimulating the production of mucins by intestinal epithelium and improve the tissue repair of the damaged epithelium. If the substance still presents an antioxidant activity, could reduce the oxidative tissue stress and consequently the epithelial damage caused by overproduction of $\operatorname{ROS}^{23}$.

SCF is a cytoprotective agent that has been used for more than three decades in the treatment of several disorders such gastritis, duodenal, stress ulcers, burns, skin lesions, and DII ${ }^{14-}$ 18,32. SCF does not have any adverse effects and it's use is known to have multiple beneficial effects on mucocutaneous wound healing, because the drug can induce the proliferation of dermal fibroblasts, and limiting the inflammation might decrease fibrosis formation and EGF expression as well as the expression of other factors involved in tissue repair processes ${ }^{32,33}$. Stimulating effects on vascular factors, such as angiogenesis, which play important roles in tissue repair, have been demonstrated by $\mathrm{SCF}^{14,35}$. The substance is a sucrose and sulfate-aluminum complex which, when in contact with gastrointestinal secretions, forms a viscous gel that adheres to the mucosa creating a physical barrier that protects the mucosa ${ }^{15-18}$. The complex formed, in addition to preventing the degradation of the mucus that covers the gastrointestinal epithelium has antimicrobial properties ${ }^{31,36}$. Studies have shown that SCF also has a bactericidal effect, effective against Escherichia coli, Pseudomonas aeruginosa and Staphylococcus aureus $^{37}$. SCF adheres tightly to proteins on the surface of ulcerations, mainly albumin and fibrinogen, thus forming a stable and insoluble complex, creating a protective layer that covers and protects the ulcerated epithelium. Recent studies have shown that SCF stimulates the production of prostaglandin E2 (PGE2), EGF and gastrointestinal mucus ${ }^{38}$. It has been shown that the use of SCF increase in $8 \%$ the dimension of the mucus gel layer, and increase the contents of acid mucins, sulfomucins and sialomucin, 63 and $81 \%$, respectively. Furthermore, SCF showed a marked increase in the proportion of the high-molecular-weight form of mucin ${ }^{38}$. The results indicate that the protective qualities of SCF lie mainly in its ability to enhance the mucus gel viscosity, content of mucin and its proportion in the high-molecular-weight form. Recently it was shown that the use of high concentrations of SCF decreases the production of ROS by leukocytes or by the xanthine-xanthine oxidase system after cell injury induced by $\mathrm{H}_{2} \mathrm{O}_{2}$, showing that the substance has antioxidant activity ${ }^{39}$. SCF prevented the delay of wound repair in cells damage induced by $\mathrm{H}_{2} \mathrm{O}_{2}$ probably through induction of COX-2 and an anti-apoptotic mechanism. These effects of SCF might be given through the activation of the NFkappaB pathway.

When we consider the issues involved in the pathogenesis of DC all of these pharmacological properties suggest that the use of SCF may be an interesting therapeutic strategy for treating DC. Although the application of enemas containing SCF have been used successfully for the treatment of RP, UC and other diseases associate with a formation of ulcers and erosions on colonic epithelium, to the best of our knowledge, only a single experimental study of our group and recently published evaluated the effects of this strategy in an experimental model of DC ${ }^{14,15,29}$. In this study we verified that daily use of enemas with SCF decreased epithelial loss, abscess formation in the colon crypts, inflammatory infiltrate and was able to preserve the population of goblet cells ${ }^{40}$. However, although in this study we showed that the application of enemas containing SCF was able to increase the population of goblet cells, we did not studied modifications on tissue content of neutral and acidic mucins in colonic epithelial glands.

The results of the present study confirm the beneficial effects of the use of enemas with SCF in the prevention of the most frequently found histological alterations in DC. We found that the topical application of SCF in the proposed model reduced of the crypt atrophy, neutrophil infiltration of the mucosa, and epithelial loss mainly when the substance is applied at a higher concentration and for a longer period of time. However, the improvement of the inflammatory score can be obtained when using a higher concentration of the substance and a longer intervention time. It is possible that the results could be even better if we had used a higher concentration of the substance, as well as more frequent interventions (e.g. every 12 h). Despite these aspects our findings were similar to those found by other authors who evaluated the effects of SCF on chemically-induced colitis mode $\mathrm{l}^{41}$. In the animals from the group where intervention was performed with saline, the epithelial surface was irregular, with a 
"brush border" aspect, and in some areas we observed the formation of small or larger ulcers (Fig.1A). In all animals treated with SCF, regardless of the concentration used, there was the formation of a gelatinous layer on the colonic mucosa that preserved the epithelial surface, without epithelial ulcerations (Fig. 1B).

Previous studies have shown that there is significant reduction in the content of neutral and acidic mucins in the mucosa devoid of the fecal stream ${ }^{13}$. The authors found that although there is a reduction in both types of mucins the reduction of the tissue content of acidic mucins was more important ${ }^{13}$. Subsequently, the same group studying the tissue content of both subtypes of mucins in an experimental model of DC suggested that the reduction was given, mainly at the expense of the mucins rich in sialic acid (sialomucins), usually found in the deeper regions of colonic ${ }^{5}$. The results of both studies clearly show that the derivation of fecal stream interferes with the synthesis of mucus layer that cover the intestinal mucosa. The absence of this morphofunctional barrier expose the colonic epithelial surface biological and antigens of the in the intestinal lumen, determining the onset of colitis. In this study when we evaluated the content of neutral mucins within the goblet cells throughout the length colonic glands, we verified that intervention with SCF increased the content of neutral mucin when compared to animals treated with saline intervention regardless of concentration used. The contents of neutral mucins not vary with time independent of the concentration used intervention. Similarly, with occurs with tissue content of neutral mucins we found that daily intervention with SCF can increase the tissue content of acid mucins. Other than that was verified with the content of neutral mucins, the increase in tissue content of acidic mucins was directly related to the concentration used. However, the tissue content did not change with the time of intervention. These results suggest that the use of enemas SCF is able to maintain the release of acidic mucin content in goblet cells even after 4 weeks of derivation of de fecal stream. These results showed that there application of SCF enemas maintains production of mucins from goblet cells of colon crypts. It is possible that this effect may be related protective properties of the substance to the colonic epithelium, stimulation of mucin by the cells to increase production of EGF, antibacterial action, and antioxidant effects that the substance presents, reducing the aggression by ROS.

Studies correlating tissue mucins with tissue levels of PGE-2, EGF and ROS are needed to verify if the effects of SCF are related only to increased production of mucus or even the substance can reduce levels of oxidative stress found in transit devoid of intestinal mucosa. We are currently studying in the same group of animals the tissue levels of oxidative stress, PGE2, EGF, NK-kappaB and COX-2 with immunohistochemical and biochemical techniques to assess this possibility.

\section{Conclusion}

The daily application of enemas containing sucralfate, in an experimental model of diversion colitisC, decrease the inflammatory alterations and increases tissue content of neutral and acidic mucins on colonic mucosa. The increase on tissue content of acidic mucin is related to concentration used of sucralfate.

\section{References}

1. Glotzer DJ, Glick ME, Goldman H. Proctitis following diversion of fecal stream. Gastroenterol. 1981 Mar;80(3):438-41. PMID: 7450438

2. Kiely EM, Ajayi NA, Wheeler RA, Malone M. Diversion proctocolitis: response to treatment with short-chain fatty acids. J Pediatr Surg. 2001 Oct;36(10):1514-7. PMID: 11584399.

3. Giardiello FM, Lazenby AJ, Bayless TM. The new colitides: collagenous, lymphocytic, and diversion colitis. Gastroenterol Clin North Am.1995 Set;24(3):717-29. PMID: 8809245.

4. Keli E, Bouchoucha M, Devroede G, Carnot F, Ohrant T, Cugnenc PH. Diversion-related experimental colitis in rats. Dis Colon Rectum.1997 Feb;40(2):222-8. PMID: 9075761.

5. Martinez CAR, Nonose R, Spadari APP, Máximo FR, Priolli DG, Pereira JA, Margarido NF. Quantification by computerized morphometry of tissue levels of sulfomucins and sialomucins in diversion colitis in rats. Acta Cir Bras. 2010 Jun;25(3):231-40. doi: 10.1590/S0102-86502010000300004.

6. Deplancke B, Gaskins HR. Microbial modulation of innate defense: goblet-cells and the intestinal mucus layer. Am J Clin Nutr. 2001 Jun;73(6):1131S-1141S. PMID: 11393191.

7. Finnie IA, Dwarakanath AS, Taylor BA, Rhodes JM. Colonic mucins synthesis is increased by sodium butyrate. Gut. 1995 Jan;36(1):939. PMID: 7890244.

8. Gaudier E, Rival M, Buisine M, Robineau I, Hoebler C. Butyrate enemas upregulate Muc genes expression but decrease adherent mucus thickness in mice colon. Physiol Res. 2009;58(1):111-9. PMID: 18198997.

9. Croix JA, Carbonero F, Nava GM, Russell M, Greenberg E, Gaskins HR. On the relationship between sialomucin and sulfomucin expression and hydrogenotrophic microbes in the human colonic mucosa. PLoS One. 2011;6(9):e24447. doi: 10.1371/journal.pone.0024447.

10. Agawa S, Muto T, Morioka Y. Mucin abnormality of colonic mucosa in ulcerative colitis associated with carcinoma and/or dysplasia. Dis Colon Rectum. 1988 May;31(5):387-9. PMID: 2452723.

11. Dorofeyev AE, Vasilenko IV, Rassokhina OA, Kondratiuk RB. Mucosalbarrierinulcerative colitis and Crohn's disease. Gastroenterol Res Pract.2013;2013:431231. doi: 10.1155/2013/431231.

12. Habib NA, Dawson PM, Krausz T, Blount MA, Kersten D, Wood CB. A study of histochemical changes in mucus from patients with ulcerative colitis, Crohn's disease, and diverticular disease of the colon. Dis Colon Rectum. 1986 Jan;29(1):15-7. PMID: 3940799.

13. Nonose R, Spadari APP, Priolli D, Máximo FR, Pereira JA, Martinez CAR. Tissue quantification of neutral and acid mucins in the mucosa of the colon with and without fecal stream in rats. Acta Cir Bras. 2009 Jul-Ago;24(4):267-75. doi: 10.1590/S0102-86502009000400005.

14. Masuelli L, Tumino G, Turriziani M, Modesti A, Bei R. Topical use of sucralfate in epithelial wound healing: clinical evidence and molecular mechanisms of action. Recent Pat Inflamm Allergy Drug Discov.2010 Jan;4(1):25-36. PubMed PMID: 19832693.

15. Gupta PJ, Heda PS, Shrirao SA, Kalaskar SS. Topical sucralfate 
treatment of anal fistulotomy wounds: a randomized placebocontrolled trial. Dis Colon Rectum. 2011 Jun;54(6):699-704. doi: 10.1007/DCR.0b013e31820fcd89.

16. Kochhar R, Mehta SK, Aggarwal R, Dhar A, Patel F. Sucralfate enema in ulcerative rectosigmoid lesions. Dis Colon Rectum. 1990 Jan;33(1):49-51. PubMed PMID: 2295277.

17. Wright JP, Winter TA, Candy S, Marks IS. Sucralfate and methylprednisolone enemas in active ulcerative colitis: a prospective, single-blind study. Dig Dis Sci. 1999 Sep;44(9):1899901. PMID: 10505732.

18. Matsuu-Matsuyama M, Shichijo K, Okaichi K, Ishii K, Wen CY, Fukuda E, Nakayama T, Nakashima M, Okumura Y, Sekine I. Sucralfate protects intestinal epithelial cells from rediation-induced apoptosis in rats. J Radiat Res. 2006 Mar;47(1):1-8. PMID: 16571913.

19. Gilks CB, Reid PE, Clement PB, Owen DA. Simple procedure for assessing relative quantities of neutral and acidic sugars in mucin glycoproteins: its use in assessing cyclical changes in cervical mucins. J Clin Pathol. 1988 Sep;41(9):1021-4. PMID: 3192745.

20. Oliveira-Neto JP, Aguilar-Nascimento JE. Intraluminal irrigations with fibers improves inflammation and atrophy in diversion colitis. Nutrition. 2004 Feb;20(2):197-9. PMID: 14962686.

21. Roediger WE. The starved colon - diminished mucosal nutrition, diminished absorption, and colitis. Dis Colon Rectum. 1990 Oct;33(10):858-62. PMID: 2209275.

22. Sousa MV, Priolli DG, Portes AV, Cardinalli IA, Pereira JA, Martinez CAR. Evaluation by computerized morphometry of histopathological alterations of the colon wall in segments with and without intestinal transit in rats. Acta Cir. Bras. 2008 SeptOct;23(5):417-24. doi: 10.1590/S0102-86502008000500005.

23. Martinez CAR, Ribeiro ML, Gambero A, Miranda DDC, Pereira JA, Nadal SR. The importance of oxygen free radicals in the etiopathogenesis of diversion colitis in rats. Acta Cir Bras. 2010 Oct;25(5):387-395. doi: 10.1590/S0102-86502010000500002.

24. Martinez CAR, Fabris FM, Silva CMG, Rodrigues MR, Sato DT, Ribeiro ML, Pereira JA. Oxidative stress and changes in the content and pattern of tissue expression of $\beta$-catenin protein in diversion colitis. J. Coloproctol (Rio J.). 2012;32(4):343-58. doi: 10.1590/ S2237-93632012000400001.

25. Kadri CJ, Pereira JA, Silva CM, Nonose R, Nascimento EF, Jacomo $\mathrm{Al}$, Martinez CA. E-cadherin expression in colonic mucosa with and without fecal stream. J Invest Surg. 2013 Apr;26(2):72-9. doi: 10.3109/08941939.2012.693334.

26. Caltabiano C, Máximo FR, Spadari AP, da Conceição Miranda DD, Serra MM, Ribeiro ML, Martinez CA. 5-aminosalicylic acid (5-ASA) can reduce levels of oxidative DNA damage in cells of colonic mucosa with and without fecal stream. Dig Dis Sci. 2011 Apr;56(4):1037-46. doi: 10.1007/s10620-010-1378-z.

27. Martinez CA, de Almeida MG, da Silva CM, Ribeiro ML, da Cunha FL, Rodrigues MR, Sato DT, Pereira JA. Enemas with $\mathrm{N}$-acetylcysteine can reduce the level of oxidative damage in cells of the colonic mucosa diverted from the faecal stream. Dig Dis Sci. 2013 Dec;58(12):3452-9. doi: 10.1007/s10620-013-2768-9.

28. Roediger WE, Nance S. Metabolic induction of experimental ulcerative colitis by inhibition of fatty acid oxidation. Br J Exp Pathol. 1986 Dec;67(6):773-82. PMID: 3099821.

29. Shimotoyodome A, Meguro S, Hase T, Tokimitsu I, Sakata T. Short chain fatty acids but not lactate or succinate stimulate mucus release in the rat colon. Comp Biochem Physiol A Mol Integr Physiol. 2000 Apr;125(4):525-31. PMID: 10840229.

30. Gaudier E, Jarry A, Blottière HM, de Coppet P, Buisine MP, Aubert JP, Laboisse C, Cherbut C, Hoebler C. Butyrate specifically modulates MUC gene expression in intestinal epithelial goblet cells deprived of glucose. Am J Physiol Gastrointest Liver Physiol. 2004
Dec;287(6):G1168-74. PMID: 15308471.

31. Johansson ME, Gustafsson JK, Holmén-Larsson J, Jabbar KS, Xia L, Xu H, Ghishan FK, Carvalho FA, Gewirtz AT, Sjövall H, Hansson GC. Bacteria penetrate the normally impenetrable inner colon mucus layer in both murine colitis models and patients with ulcerative colitis. Gut. 2014 Fev;63(2):281-91. doi: 10.1136/gutjnl-2012-303207.

32. Beheshti A, Shafigh Y, Zangivand AA, Samiee-Rad F, Hassanzadeh G, Shafigh N. Comparison of topical sucralfate and silver sulfadiazine cream in second degree burns in rats. Adv Clin Exp Med. 2013 Jul-Aug;22(4):481-7. PMID: 23986207.

33. Burch RM, McMillan BA. Sucralfate induces proliferation of dermal fibroblasts and keratinocytes in culture and granulation tissue formation in full-thickness skin wounds. Agents Actions. 1991 Sept;34(1-2):229-31. PMID: 1793036.

34. Folkmann J, Szabo S, Stovroff M, McNeil P, Li W, Shing Y. Duodenal ulcer. Discovery of a new mechanism and development of angiogenic therapy that accelerates healing. Ann Surg. 1991 Oct;214(4):414-25. PMID: 1719945.

35. Szabo S, Vattay P, Scarbrough E, Folkman J. Role of vascular factors, including angiogenesis, in the mechanisms of action of sucralfate. Am J Med. 1991 Aug 8;91(2A):158S-160S. PMID: 1715670.

36. Bragman SG, Pankhurst CL, Casewell MW. Activity of sucralfate (sucrose octa-sulphate), an anti-ulcer agent, against opportunistic gram-negative bacilli. J Antimicrob Chemother. 1995 Oct;36(4):7036. PMID: 8591945.

37. West AP, Abdul S, Sherratt MJ, Inglis TJ. Antibacterial activity of sucralfate against Escherichia coli, Staphylococcus aureus and Pseudomonas aeruginosa in batch and continuous culture. Eur J Clin Microbiol Infect Dis.1993 Nov;12(11):869-71. PMID: 8112362.

38. Slomiany BL, Piotrowski J, Okazaki K, Grzelinska E, Slomiany A. Nature of the enhancement of the protective qualities of gastric mucus by sucralfate. Digestion. 1989;44(4):222-31. PMID: 2483693.

39. Laudanno OM, Bedini OA, Cesolari JA, San Miguel P. Evidence of anti-oxidant role of sucralfate in gastric mucosal protection. Ital J Gastroenterol. 1990 Feb;22(1):19-21. PMID: 2131922.

40. Pereira JA, Rodrigues MR, Sato DT, Silveira Junior PP, Dias AM, Silva CG, Martinez CAR. Evaluation of sucralfate enema in experimental diversion colitis. J. Coloproctol. (Rio J.).2013 NovDez;33(4):182-90. doi: 10.1016/j.jcol.2013.08.005.

41. Zahavi I, Avidor I, Marcus H, Rosenbach Y, Waisman Y, Ligumsky M, Dinari G. Effect of sucralfate on experimental colitis in the rat. Dis Colon Rectum. 1989 Feb;32(2):95-8. PMID: 2914534.

\section{Correspondence:}

Carlos Augusto Real Martinez

Rua Rui Barbosa, 255/32

09190-370 São Paulo - SP Brasil

Tel.: (55 11)4438-9203

carmartinez@uol.com.br

Received: Apr 15, 2014

Review: Jun 17, 2014

Accepted: July 14, 2014

Conflict of interest: none

Financial source: Sao Paulo Research Foundation (FAPESP). Project $N^{\circ}$. 2010/12492-7

${ }^{1}$ Research performed at Laboratory of Medical Investigation, Medical School, Sao Francisco University (USF), Bragança Paulista-SP, Brazil. Part of Master degree thesis, Postgraduate Program in Health Sciences, USF. Tutor: Carlos Augusto Real Martinez. 